\title{
Analysis of the Factors Affecting Surgical Success of Implants Placed in Iranian Warfare Victims
}

\author{
Mohammad Jafarian ${ }^{\mathrm{a}}$ Mohammad Bayat ${ }^{\mathrm{b}}$ Amir-Hossein Pakravan ${ }^{\mathrm{c}}$ \\ Naghmeh Emadi ${ }^{d}$ \\ a Department of Oral and Maxillofacial Surgery, Dental Research Center, Dental School, Shahid Beheshti University \\ of Medical Sciences, ${ }^{b}$ Department of Oral and Maxillofacial Surgery, Dental School, Tehran University of Medical \\ Sciences, Tehran, ' Department of Oral and Maxillofacial Surgery, Dental School, Mazandaran University of Medical \\ Sciences, Sari, and dDepartment of Dental Research Center, Dental School, Shahid Beheshti University of Medical \\ Sciences, Tehran, Iran
}

\section{Key Words}

Dental implants · Survival rate · Failure · Risk factors

\begin{abstract}
Objective: The aim was to evaluate the survival time and success rates of dental implants in warfare victims and factors that affect implant success. Subjects and Methods: This retrospective study involved 250 Iranian warfare victims who received dental implants from 2003 to 2013. Patients' demographic characteristics, as well as the brand, diameter, length, location and failure rate of the implants were retrieved from patients' dental records and radiographs. The associations between these data and the survival rate were analyzed. Statistical analysis was carried out with $x^{2}$ and logrank tests. Results: Overall, out of the 1,533 dental implants, 61 (4\%) failed. The maxillary canine area had the highest failure rate [9 of 132 implants (6.8\%)], while the mandibular incisor region had the least number of failures [ 3 of 147 implants (2.0\%)] and the longest survival time (approximately 3,182 days). Maxillary canine areas had the shortest survival (about 2,996 days). The longest survival time was observed in implants with $11 \mathrm{~mm}$ length $(3,179.72 \pm 30.139$ days $)$ and $3.75-$ $4 \mathrm{~mm}$ diameter $(3,131.161 \pm 35.96$ days $)$, and the shortest
\end{abstract}

survival was found in implants with $11.5 \mathrm{~mm}$ length $(2,317.79$ \pm 18.71 days) and $6.5 \mathrm{~mm}$ diameter (2,241.45 \pm 182.21 days). Moreover, implants with $10 \mathrm{~mm}$ length (10.7\%) and 5.5-6 $\mathrm{mm}$ diameter (22.2\%) had the highest failure rate; however, the least failure rate occurred when the implants were 11.5 $\mathrm{mm}$ in length (1.9\%) and 3-3.5 mm in diameter (3.1\%). Conclusions: The brand, length and diameter of implants affected the survival time, failure rate and time to failure. The location of the implant was not statistically significant regarding the mentioned factors, although it has clinical significance.

(c) 2016 S. Karger AG, Basel

\section{Introduction}

Maxillofacial reconstruction in warfare victims has always been interesting for the oral and maxillofacial surgeons. Warfare victims require special attention. Complex treatments are carried out to reconstruct hard and soft tissue defects. Some of these victims have foreign metal fragments present in the maxillofacial skeleton, such as shrapnel, gunshot and particles that unfortunately cannot be removed [1]. The bone-grafted areas are usually deficient in ridge height, width, and bone quality. The

\begin{tabular}{ll}
\hline KARGER & $\begin{array}{l}\text { ( ) 2016 S. Karger AG, Basel } \\
1011-7571 / 16 / 0255-0449 \$ 39.50 / 0 \quad \text { Karger }\end{array}$ \\
$\begin{array}{l}\text { E-Mail karger@karger.com } \\
\text { www.karger.com/mpp }\end{array}$ & $\begin{array}{l}\text { Thisis an Open Access article licensed under the terms of the } \\
\text { Creative Commons Attribution-NonCommercial 3.0 Un- } \\
\text { ported license (CC BY-NC) (www.karger.com/OA-license), } \\
\text { applicable to the online version of the article only. Distribu- } \\
\text { tion permitted for non-commercial purposes only. }\end{array}$
\end{tabular}

Naghmeh Emadi

Department of Dental Research Center

Dental School, Shahid Beheshti University of Medical Sciences

Evin, 1983963113 Tehran (Iran)

E-Mail emadi_ne@yahoo.com 
altered morphology, blood supply and thickness of hard and soft tissues make prosthodontic treatments difficult. Furthermore, medication taken by the victims can sometimes cause limitations in the success of implant prosthodontic treatments $[1,2]$.

In addition to the above-mentioned, there are many related factors that can contribute to implant failure, such as host characteristics (age, gender, systemic disease, smoking and oral hygiene), type of implant (brand), factors related to implant placement site (position in the arch, bone quality and bone quantity), and surgical factors such as the initial stability, and angulations [3-5]. Different implant failure rates had been reported in previous studies for short and long implants as well as the above-mentioned risk factors [6, 7]. A retrospective study in 2016 evaluated the success rate of 164 dental implants after using bone grafts. The survival rate was $97 \%$. They concluded that implants placed in augmented bone gave similar results to implants inserted in nonaugmented regions [8]. Degidi et al. [9] reported a higher success rate of approximately $97.7 \%$ for 133 short dental implants that were immediately loaded.

However, the samples in these studies consisted of normal people. Since a limited number of studies have investigated the success rate of dental implants in warfare victims [1], we therefore aimed to study various brands and types of dental implants in Iranian warfare victims.

\section{Subjects and Methods}

In this retrospective study, 250 warfare victims suffering from maxillofacial, mental and psychological, spinal or chemical trauma were evaluated. All warfare victims who had medical records in the Ghazi Tabatabaei clinic and had undergone implant placement between 2003 and 2013 were included. The treatments had been performed by two experienced oral and maxillofacial surgeons (M.J. and M.B.) with hands-on experience in the treatment of maxillofacial war injuries. Patients were followed up more than four times during the first year after implant placement (after 1 week, 1,3 , and 6 months and sometimes even after 8/9 months, based on the patient's status). After attaching the prosthetic part of the implant, the patients received a thorough oral and clinical examination, radiographic evaluation and assessment of plaque control several times throughout the first year. The patients' records were assessed and some information including the patients' demographic characteristics, the brand, diameter, length, location and time to failure of implants were extracted and transferred to a prepared questionnaire. Six brands of dental implant systems were installed: F2 (FRIALIT implants, DENTSPLY implants, Germany), NB (Brånemark System, Nobel Biocare, Sweden), MKIII (Brånemark System, MKIII, Sweden), BH (BioHorizons implant systems, USA), 3i (Biomet 3i, Palm Beach, Fla., USA) and Xive (Dentsply, Friadent, Mannheim, Germany). Patients were divided into 9 groups based on implant length $(7-8.5,9.0,9.5,10.0,11.0,11.5,12,13$, and 15 $\mathrm{mm}$ ), and 5 groups were formed based on the diameter of implants $(3-3.5,3.75-4,4.5-5,5.5-6,6.5 \mathrm{~mm})$. In terms of the location of implants, 8 groups were formed, 4 in each jaw (maxilla and mandible). Each jaw was further subdivided into molar, premolar, canine and incisor regions. An exclusion criterion was incomplete medical and dental records. Complications or failures were managed and noted by a specialist, and the chart was completed accordingly. The survival criteria were based on those proposed by Buser et al. in 1997 and by Cochran et al. in 2002 [10] and consisted of the absence of the following: persistent subjective complaints, such as pain, foreign body sensation, and/or dysesthesia; recurrent peri-implantitis with suppuration; mobility; a continuous radiolucency around the implant and no rapid progressive bone loss and possibility of restoration.

Implants with the above-mentioned symptoms were discovered and the survival period was calculated from the time of implant placement until failure or the most recent follow-up.

\section{Statistical Analysis}

The relevant data were entered into SPSS version 17 software (SPSS, Chicago, Ill., USA) and analyzed using the $\chi^{2}$ and Fisher's exact tests. An a value $<0.05$ was considered statistically significant. Additionally, the log-rank Kaplan-Meier analysis (MantelCox test) confirmed the effect of the factors (brand, length, diameter and location) on the survival rate $(\mathrm{p}<0.01)$.

\section{Results}

The 250 patients had a mean age of $50 \pm 9.1$ years at the time of surgery and 1,533 implants. Of the 1,533 implants, 61 (4\%) were failures. The mean survival time was $1,648 \pm 649.505$ days. Information regarding the type of war injury repetition is summarized in table 1 . The soft tissues had surface irregularities and showed excessive scarring. Gingival hyperplasia, lack of keratinized gingiva, high muscle attachments, inadequate sulcus depth, restricted tongue movement due to scar tissue formation, skin grafts at the surgical site, and poor oral hygiene were also noted in these patients. 211 warfare victims had previously undergone multiple, successive surgeries for their injuries and were then referred for maxillofacial implant reconstruction. Limitation in mouth opening, which was common in these patients due to the presence of dense fibrotic scars as a result of multiple soft tissue surgeries and altered bone anatomy, affected surgical and prosthodontic treatment planning in $70 \%$ of them. $89 \%$ of the patients had unsatisfactory oral hygiene. The poor oral hygiene was not entirely attributable to lack of motivation, instead of other factors such as physical disability, inevitable food impaction due to a nonfunctional vestibule, and/or scarred, defective, or nerve-damaged tongue all contributed to poor oral hygiene. Twelve victims with 
Table 1. Implant failure based on the type of injury

\begin{tabular}{lcrr}
\hline Injuries & \multicolumn{2}{l}{ Failure } & \multirow{2}{*}{ Total } \\
\cline { 2 - 3 } & no & yes \\
\hline Maxillofacial & $567(94.3 \%)$ & $34(5.7 \%)$ & 601 \\
Mental and psychological & 27 & 0 & 27 \\
Maxillofacial and chemical & 110 & 0 & 110 \\
Maxillofacial and spinal & $4(80.0 \%)$ & $1(20.0 \%)$ & 5 \\
Maxillofacial, mental and psychological & $316(98.1 \%)$ & $6(1.9 \%)$ & 322 \\
Maxillofacial, mental and psychological, chemical & $129(96.3 \%)$ & $5(3.7 \%)$ & 134 \\
Maxillofacial, mental and psychological, spinal & 21 & 0 & 21 \\
Maxillofacial, mental and psychological, spinal or chemical & 22 & 0 & 22 \\
\hline
\end{tabular}

Table 2. Survival time and failure rate based on the brand of implant

\begin{tabular}{lccl}
\hline Brand & $\begin{array}{l}\text { Placed } \\
\text { implant, n }\end{array}$ & $\begin{array}{l}\text { Failure rate } \\
\text { (frequency) }\end{array}$ & $\begin{array}{l}\text { Survival time, } \\
\text { mean } \pm \text { SD, days }\end{array}$ \\
\hline 3i & 583 & $19(3.3 \%)$ & $2,288.00 \pm 16.25$ \\
Xive & 461 & $12(2.6 \%)$ & $2,381.27 \pm 16.52$ \\
F2 & 163 & $17(10.4 \%)$ & $3,000.97 \pm 60.125$ \\
BH & 244 & $11(4.5 \%)$ & $2,853.19 \pm 36.87$ \\
MKIII & 68 & $1(1.5 \%)$ & $2,375.00 \pm 33.74$ \\
NB & 14 & $1(7.1 \%)$ & $2,024.28 \pm 134.63$ \\
\hline Total & 1,533 & $61(4 \%)$ & \\
\hline p value & & 0.001 & 0.001 \\
\hline
\end{tabular}

amputated hands and $10 \%$ with limited physical activity due to spinal injury were incapable of brushing their teeth. Fisher's exact test revealed that the success or failure of implants was significantly associated with the type of injury received $(\mathrm{p}<0.01)$, and the highest rate of failure $(20 \%)$ was observed in warfare victims with concomitant maxillofacial and spinal injuries. Those suffering from maxillofacial injuries alone ranked second in this respect.

\section{Implant Brand}

Implant brand led to significantly different results: F2 implants $(3,000.97 \pm 60.125$ days $)$ and NB $(2,024.28 \pm$ 134.630 days) showed the highest and lowest survival time, respectively. The association between the survival time and brand of implants was statistically significant $(\mathrm{p}=0.019) . \mathrm{F} 2(10.4 \%)$ had the highest and MKIII $(1.5 \%)$ had the lowest failure rate and the difference between the two was statistically significant $(\mathrm{p}=0.001)$. Additionally,
Table 3. Survival time and failure rate according to implant length

\begin{tabular}{lccc}
\hline $\begin{array}{l}\text { Length, } \\
\text { mm }\end{array}$ & $\begin{array}{l}\text { Placed } \\
\text { implant, } \mathrm{n}\end{array}$ & $\begin{array}{l}\text { Failure rate } \\
\text { (frequency) }\end{array}$ & $\begin{array}{l}\text { Survival time, } \\
\text { mean } \pm \text { SD, days }\end{array}$ \\
\hline $7-8.5$ & 43 & $2(4.5 \%)$ & $2,658.88 \pm 82.95$ \\
9 & 57 & $5(8.5 \%)$ & $2,721.78 \pm 106.06$ \\
9.5 & 64 & $2(3.1 \%)$ & $2,369.047 \pm 43.86$ \\
10.0 & 112 & $12(10.7 \%)$ & $2,881.58 \pm 98.19$ \\
11.0 & 235 & $5(2.1 \%)$ & $3,179.72 \pm 30.139$ \\
11.5 & 264 & $5(1.9 \%)$ & $2,317.79 \pm 18.71$ \\
12 & 186 & $6(3.2 \%)$ & $2,890.55 \pm 35.27$ \\
13 & 494 & $16(3.2 \%)$ & $3,142.47 \pm 25.75$ \\
15 & 78 & $8(10.3 \%)$ & $2,944.22 \pm 102.17$ \\
\hline Total & 1,533 & $61(4 \%)$ & \\
\hline p value & \multicolumn{5}{c}{0.001} \\
\hline
\end{tabular}

the longest time to failure in terms of brand was observed in F2 (967.3 days), Xive (222.4 days), BH (209.5 days) and 3i (191.8 days) implants $(\mathrm{p}=0.001)($ table 2$)$.

\section{Implant Length}

The longest survival time was observed in the 11-mm implants $(3,179.72 \pm 30.139$ days $)$ and the shortest in the 11.5 -mm implants $(2,317.79 \pm 18.71$ days $)$. The highest and lowest failure rates were found in the 10 - and $11.5-\mathrm{mm}$ implants, respectively. This difference was also significant $(\mathrm{p}=0.001)$. The longest and shortest time to failure was observed in the $10-\mathrm{mm}(810.1 \pm 1,006.6$ days $)$ and $11.5-\mathrm{mm}$ (131.6 \pm 110.2 days) implants, respectively, and the difference between them was significant $(\mathrm{p}=0.001)$ (table 3$)$.

\section{Implant Diameter}

The longest and shortest survival times were observed in the 3.75- to 4 - and 6.5 - $\mathrm{mm}$ diameter implants. The dif- 
Table 4. Survival time and failure rate according to implant diameter

\begin{tabular}{lccc}
\hline $\begin{array}{l}\text { Diameter, } \\
\mathrm{mm}\end{array}$ & $\begin{array}{l}\text { Placed } \\
\text { implant, } \mathrm{n}\end{array}$ & $\begin{array}{l}\text { Failure rate } \\
\text { (frequency) }\end{array}$ & $\begin{array}{l}\text { Survival time, } \\
\text { mean } \pm \mathrm{SD} \text {, days }\end{array}$ \\
\hline $3-3.5$ & 225 & $7(3.1 \%)$ & $2,888.99 \pm 33.13$ \\
$3.75-4$ & 1,015 & $38(3.7 \%)$ & $3,131.161 \pm 35.96$ \\
$4.5-5$ & 264 & $10(3.8 \%)$ & $3,128.21 \pm 19.23$ \\
$5.5-6$ & 18 & $4(22.2 \%)$ & $2,869.39 \pm 182.21$ \\
6.5 & 11 & $7(18.2 \%)$ & $2,241.45 \pm 182.21$ \\
\hline Total & 1,533 & $61(4 \%)$ & \\
\hline p value & & 0.001 & 0.003 \\
\hline
\end{tabular}

Table 5. Survival time and failure rate according to implant location

\begin{tabular}{lccr}
\hline Location & $\begin{array}{l}\text { Placed } \\
\text { implant, n }\end{array}$ & $\begin{array}{r}\text { Failure rate } \\
\text { (frequency) }\end{array}$ & $\begin{array}{l}\text { Survival time, } \\
\text { mean } \pm \text { SD, days }\end{array}$ \\
\hline Molar-maxilla & 201 & $13(6.5 \%)$ & $3,015.005 \pm 65.50$ \\
Premolar-maxilla & 237 & $10(4.2 \%)$ & $3,119.46 \pm 39.52$ \\
Canine-maxilla & 132 & $9(6.8 \%)$ & $2,996.66 \pm 66.24$ \\
Incisor-maxilla & 198 & $8(4.0 \%)$ & $3,051.43 \pm 54.13$ \\
Molar-mandible & 274 & $9(3.3 \%)$ & $3,065.75 \pm 33.18$ \\
Premolar-mandible & 230 & $6(2.6 \%)$ & $3,164.79 \pm 33.13$ \\
Canine-mandible & 114 & $3(2.6 \%)$ & $3,164.30 \pm 47.11$ \\
Incisor-mandible & 147 & $3(2.0 \%)$ & $3,182.23 \pm 37.01$ \\
\hline Total & 1,533 & $61(4 \%)$ & \\
\hline p value & \multicolumn{5}{c}{0.200} & 0.200 \\
\hline
\end{tabular}

ference was also statistically significant $(\mathrm{p}=0.003)$. In addition, the 5.5- to 6-mm diameter implants showed the highest, while the 3- to $3.5-\mathrm{mm}$ diameter implants had the lowest failure rate. This difference was statistically significant ( $p=0.001)$. Furthermore, the shortest and longest time to failure was observed in the $3-$ to $3.5-\mathrm{mm}$ $(117.1 \pm 100.6$ days $)$ and in the 5.5 - to 6 - $\mathrm{mm}$ diameter implants $(1,883.2 \pm 1,087.5$ days $)$ with a statistical difference of $\mathrm{p}=0.003$ (table 4 ).

\section{Implant Location}

The longest survival time was seen in implants inserted at the site of mandibular incisors and the shortest was seen in the canine region. However, the association between the survival time and site of implants was not statistically significant $(\mathrm{p}=0.20)$. The failure rate in the canine and molar maxillary areas was 6.8 and $6.5 \%$, respec- tively. This rate was $2.0 \%$ in the mandibular incisor area. However, this difference was not statistically significant $(\mathrm{p}=0.20)($ table 5).

The brand was not associated with the length, diameter or site of the implants $(\mathrm{p}>0.05)$.

\section{Discussion}

In the present study, the failure rate was $4 \%$ and the mean survival time was $1,648 \pm 649.505$ days ( 4.5 years). This failure rate was similar to the $4.8 \%$ reported by Kalantar et al. [1], and the rate of failure was higher (20\%) in warfare victims with concomitant maxillofacial/spinal injuries compared to healthy subjects. Predictably, a study by Degidi et al. [9] investigating implant success in normal patients reported a low failure rate of $2.3 \%$. Additional factors that could exacerbate the situation in warfare victims are the higher stress levels and altered occlusion which might induce subsequent development of parafunctional habits. This leads to overloading of the implant, which is considered the most important factor that causes implant failure $[11,12]$. Apart from poor oral hygiene, limitation in mouth opening due to the presence of scar tissue and lower attendance to follow-up visits could also be factors that contribute to the high prevalence of implant failure.

In terms of implant length, the highest failure rate was reported in $10-\mathrm{mm}(10.7 \%)$ and $15-\mathrm{mm}$ (10.3\%) implants, while the lowest failure rate was observed in 11.5$\mathrm{mm}$ implants (1.9\%). Dental implants are accessible in lengths of $6-20 \mathrm{~mm}$; the size of $10-16 \mathrm{~mm}$ is most widely used [13]. Short implants, usually considered less than 10 $\mathrm{mm}$, were often used in the places where there is not enough bone [14]. In this study, similar to some studies, 10 -mm implants (short) have a relatively high failure rate $[13,15,16]$.

However, a systematic review controversially reported that the success of short implants was highly predictable, with a survival rate of approximating $99.1 \%$ after 3.2-1.7 years of follow-up. They also recommended the placement of short implants in atrophic alveolar ridges as a successful alternative treatment option in the short term; they also noted that further scientific evidence was required to cast a judgment for their long-term success [7]. Another systematic review demonstrated successful placement of short implants in partially edentulous patients, despite the presumably higher survival rate of long implants [17]. The difference in results between the aforementioned research and this study (higher failure 
rate for short implants) may be that out of the 12 failures, 10 occurred in the maxilla out of which 8 had been inserted in the posterior maxilla and in 2 cases, bone grafting, in 3 cases bone expansion and in another 2 cases sinus lifting had been performed. Lower quality of the bone in the posterior maxilla and areas of grafting or sinus lifting can be responsible for the higher failure rate of $10-\mathrm{mm}$ implants. Moreover, this study had a longer follow-up period unlike previous studies. The ideal length suggested for an implant is $12 \mathrm{~mm}$, concurring with our study results that found the lowest failure rate in $11.5 \mathrm{~mm}$ implants [18]. The higher failure rate in 15$\mathrm{mm}$ implants may be due to the risk of overheating during drilling which is the most important cause of surgical failure of implants [19].

In this study, the association between the survival time and brand of implant was statistically significant; F2 and NB showed the highest and lowest survival time, respectively. F2 had the highest and MKIII had the lowest failure rate, and the longest time to fail in terms of brand was observed in F2, BH, 3i and Xive implants. Esposito et al. [20] assessed 6 brands (Astra TiOblast/Branmark standard and MKII/IMZ titanium plasma spray/ITI TPS hallow titanium/southern sand blast acid etched/steri Oss HL series) and reported contradictory findings compared to this study, with no clinical differences between implant systems. Zupnik et al. [21] compared two systems (Sandblasted and Straumann/TiUnite, Nobel Biocare) and similar to this study, one type of implant tended to have a higher failure rate. Well-conducted long-term randomized clinical trials are necessary to compare the efficacy of the various implant systems and provide indisputable evidence.

In the category of diameter, implants are divided into 4 groups (mini, narrow, standard and wide). Implants with a diameter of less than $3.75 \mathrm{~mm}$ are considered as narrow, whereas those that are $5 \mathrm{~mm}$ or greater in diameter are wide implants [13]. According to our findings, the highest and lowest survival times were seen in implants with 3.75- to 4-mm and 6-mm diameters, respectively. The highest and lowest failure rates were observed in implants with 5.5- to 6- $\mathrm{mm}$ and 3- to 3.5- $\mathrm{mm}$ diameters, respectively. Research supports this finding; it demonstrated the least amount of stress in implants with 3.6to $4.2-\mathrm{mm}$ diameters [22]. In the study by Renouard and Nisand [6], a higher failure rate was reported for wide implants similar to this study. The higher failure rate in wide dental implants compared to standard or narrow implants is attributed to the possible lower quality of bone; however, they are utilized as a replacement for an

Factors Affecting Surgical Success of Implants in Warfare Victims implant with a smaller diameter (in case of lack of stability), lower thickness/height of the residual bone and stress-shielding phenomenon. A further study not only observed that shorter implants had a lower survival rate than longer ones, but that 3-mm diameter implants had a lower survival rate than those with 4-mm diameter contradicting our findings [23]. Different types of implants used, surgical technique, and patient-related factors may be responsible for such discrepancies.

In our study, the results revealed that failures mostly occur in the canine $(6.8 \%)$ and molar (6.5\%) maxillary areas, with the least occurrence in the mandibular incisor region $(2.0 \%)$. However, the association between the location of dental implant placement and failure rate was not statistically significant, consistent with previous reports [24,25]. Lower success and survival rates of posterior implants particularly in the posterior maxilla, undoubtedly due to the disadvantages of type IV bone in this area, have been reported in several studies [15, 26]. A study in 2014 explained that the failure rate of implants in the anterior region of the maxilla was significantly higher than in other locations consistent with our study (anterior region consists of canine area). In the anterior maxilla, called the traumatic zone, buccal bone resorption after traumatic force could lead to problems in treatment and contribute to implant failures. Furthermore, eccentric stress on the maxillary canine is another possible reason [13]. Also, the buccal plate canine area was naturally thinner than other locations in the anterior region that has an impact on the failure rate.

The anterior mandible, called the interforaminal zone, also presents ideal density of the bone for implant support. The possibility of success is higher than in other regions, regardless of implant type, surface topography, and prosthesis design, with success rates of $90-100 \%$ [27]. Our investigation showed a success rate of $98 \%$ in the interforaminal zone, higher than in other regions, confirming this estimate. However, a direct association between the implant site and failure rate has yet to be clearly established [28].

A limitation in this study is that implant-related risk factors were not evaluated. In some studies, smoking and periodontitis have been considered as factors that have an effect on the survival rate. Although there is evidence supporting the reduced implant survival due to smoking, periodontitis is a common cause of tooth loss $[29,30]$ that seems not to be a significant risk factor for implant failure but may affect the implant success rate in the long term [5]. 


\section{Conclusions}

In this study, implants placed in warfare victims had a favorable outcome in terms of function, comparable to that in normal edentulous patients. The overall success rate for the implants during the follow-up period was high, with a mean survival time of 4.5 years. The location of implants had no statistically significant effect. However, implants placed in the posterior maxilla had a higher overall failure rate, although this difference was not statistically significant and the highest rate of failure was seen in warfare victims with maxillofacial and spinal injuries.

\section{References}

1 Motamedi MHK, Hashemi HM, Shams MG, et al: Rehabilitation of war-injured patients with implants: analysis of 442 implants placed during a 6-year period. J Oral Maxillofac Surg 1999;57:907-913.

2 Gökçen-Röhlig B, Atalay B, Baca E, et al: Prosthetic rehabilitation of a patient with a mandibular defect caused by a gunshot wound. J Craniofac Surg 2009;20:1614-1617.

3 Kim SH, Kim S, Lee K-W, et al: The effects of local factors on the survival of dental implants: a 19-year retrospective study. J Korean Acad Prosthodont 2010;48:28-40.

4 Busenlechner D, Fürhauser R, Haas R, et al: Long-term implant success at the Academy for Oral Implantology: 8-year follow-up and risk factor analysis. J Periodontal Implant Sci 2014;44:102-108.

-5 Al-Sabbagh M, Bhavsar I: Key local and surgical factors related to implant failure. Dent Clin North Am 2015;59:1-23.

6 Renouard F, Nisand D: Impact of implant length and diameter on survival rates. Clin Oral Implants Res 2006;17:35-51.

7 Annibali S, Cristalli M, Dell'Aquila D, et al: Short dental implants a systematic review. J Dent Res 2012;91:25-32.

8 Voss JO, Dieke T, Doll C, et al: Retrospective long-term analysis of bone level changes after horizontal alveolar crest reconstruction with autologous bone grafts harvested from the posterior region of the mandible. J Periodontal Implant Sci 2016;46:72-83.

-9 Degidi M, Piattelli A, Carinci F: Immediately loaded short implants: analysis of a case series of 133 implants. Quintessence Int 2007;38: 193-201.

10 Kim J-S, Sohn J-Y, Park J-C, et al: Cumulative survival rate of Astra Tech implants: a retrospective analysis. J Periodontal Implant Sci 2011;41:86-91.
11 Komiyama O, Lobbezoo F, De Laat A, et al: Clinical management of implant prostheses in patients with bruxism. Int J Biomater 2012; 2012:369063.

12 Chen Y-Y, Kuan C-L, Wang Y-B: Implant occlusion: biomechanical considerations for implant-supported prostheses. J Dent Sci 2008;3:65-74.

13 Geckili O, Bilhan H, Geckili E, et al: Evaluation of possible prognostic factors for the success, survival, and failure of dental implants. Implant Dent 2014;23:44-50.

14 Olate S, Lyrio MC, de Moraes M, et al: Influence of diameter and length of implant on early dental implant failure. J Oral Maxillofac Surg 2010;68:414-419.

15 Herrmann I, Lekholm U, Holm S, et al: Evaluation of patient and implant characteristics as potential prognostic factors for oral implant failures. Int J Oral Maxillofac Implants 2005; 20:220-230.

16 Grant B-TN, Pancko FX, Kraut RA: Outcomes of placing short dental implants in the posterior mandible: a retrospective study of 124 cases. J Oral Maxillofac Surg 2009;67: 713-717.

17 Telleman G, Raghoebar GM, Vissink A, et al: A systematic review of the prognosis of short $(<10 \mathrm{~mm})$ dental implants placed in the partially edentulous patient. J Clin Periodontol 2011;38:667-676.

18 Lee J-H, Frias V, Lee K-W, et al: Effect of implant size and shape on implant success rates: a literature review. J Prosthet Dent 2005;94: 377-381.

19 Sharawy M, Misch CE, Weller N, et al: Heat generation during implant drilling: the significance of motor speed. J Oral Maxillofac Surg 2002;60:1160-1169.
20 Esposito M, Grusovin MG, Coulthard P, et al: A 5-year follow-up comparative analysis of the efficacy of various osseointegrated dental implant systems: a systematic review of randomized controlled clinical trials. Int J Oral Maxillofac Implants 2004;20:557-568.

21 Zupnik J, Kim S-W, Ravens D, et al: Factors associated with dental implant survival: a 4 -year retrospective analysis. J Periodontol 2011;82:1390-1395.

22 Himmlová L, Dostálová T, Kácovský A, et al: Influence of implant length and diameter on stress distribution: a finite element analysis. J Prosthet Dent 2004;91:20-25.

23 Winkler S, Morris HF, Ochi S: Implant survival to 36 months as related to length and diameter. Ann Periodontol 2000;5:22-31.

24 McDermott NE, Chuang SK, Woo VV, et al: Complications of dental implants: identification, frequency, and associated risk factors. Int J Oral Maxillofac Implants 2003;18:848855.

25 Paquette DW, Brodala N, Williams RC: Risk factors for endosseous dental implant failure. Dent Clin North Am 2006;50:361-3671.

26 Moy PK, Medina D, Shetty V, et al: Dental implant failure rates and associated risk factors. Int J Oral Maxillofac Implants 2005;20; 569-577.

27 Attard NJ, Zarb GA: Immediate and early implant loading protocols: a literature review of clinical studies. J Prosthet Dent 2005;94:242258.

28 Guler AU, Sumer M, Duran I, et al: Resonance frequency analysis of 208 Straumann dental implants during the healing period. J Oral Implantol 2013;39:161-167.

29 Jafarian M, Etebarian A: Reasons for extraction of permanent teeth in general dental practices in Tehran, Iran. Med Princ Pract 2013;22:239-244.

30 Al-Shammari KF, Al-Ansari JM, Al-Melh M, et al: Reasons for tooth extraction in Kuwait. Med Princ Pract 2006;15:417-422. 